\title{
Study of Martensitic Transformation in 304L Austenitic Stainless Steel after Tensile and Low Cycle Fatigue Tests
}

\author{
Gláucio Soares da Fonseca ${ }^{1}$, Silvana Carreiro de Oliveira ${ }^{1}$, Jéssica Gadêlha Chaves ${ }^{1}$, Pedro Pena Leite ${ }^{1}$, Fabiane \\ Roberta Freitas Da Silva ${ }^{1} \&$ Luiz Carlos Rolim Lopes ${ }^{1}$ \\ ${ }^{1}$ Graduate Program on Metallurgical Engineering, Federal Fluminense University, Volta Redonda - Rio de \\ Janeiro, Brazil \\ Correspondence: Gláucio Soares da Fonseca, Escola de Engenharia Industrial Metalúrgica de Volta Redonda \\ (EEIMVR), Graduate Program on Metallurgical Engineering, Federal Fluminense University, Avenida dos \\ Trabalhadores, 420, Vila Santa Cecília, 27255-125, Volta Redonda, Rio de Janeiro, Brazil. Tel: \\ +55-24-2107-3728. E-mail: glaucio@metal.eeimvr.uff.br; glauciosfg11@gmail.com
}

Received: October 17, 2019

Accepted: November 27, 2019 Online Published: December 17, 2019

doi:10.5539/jmsr.v9n1p22

URL: https://doi.org/10.5539/jmsr.v9n1p22

\begin{abstract}
There are many studies on austenitic stainless steels with transformation induced plasticity (TRIP). Basically, in these steels, there is a significant increase in strength and toughness with the transformation of austenite to martensite. 304L steel finds extensive application in industry. Studies relating to martensitic transformation with plastic deformation are quite common. Many studies involve monotonic loading relating to the martensite formed. In practice, 304L steels are subject to distinct types of loading and possibly with stress concentrators. Thus, also in smaller quantities, it is possible to find in the literature studies involving cyclic loading with the TRIP effect. To contribute to the literature on the analysis of the TRIP effect on these steels, 304L steel samples with stress concentrators underwent interrupted monotonic tensile tests. Optical microscopy (OM) and x-ray diffraction (XRD) technique characterized the martensitic transformation. Other $304 \mathrm{~L}$ steel samples with a stress concentrator underwent a low cycle fatigue test. The martensitic transformation, in this case, was possible to follow with the electron backscatter diffraction technique (EBSD). The samples after the interrupted monotonic tests show a high martensite volume fraction formed $1 \mathrm{~mm}$ away from the notch (30\% to 50\%), due to the plastic deformation suffered. From $5.5 \mathrm{~mm}$ of the notch, the samples again display a microstructure like that of the as-received (AR) sample. For the low cycle fatigue tested sample, the high concentration of deformation-induced martensite was within $15 \mu \mathrm{m}$ of the discontinuity. Approximately $0.5 \mathrm{~mm}$ from the circular discontinuity, the sample again has a microstructure like the initial sample (IS).
\end{abstract}

Keywords: 304L Austenitic Stainless Steel, Trip Effects, Monotonic Tensile Test, Low Cycle Fatigue

\section{Introduction}

Austenitic stainless steels, within its class of stainless steels, are probably the most studied. These steels have an excellent combination of strength and toughness. Thus, they find extensive application in various industrial branches (Spencer, Embury, Conlon, Véron, \& Bréchet, 2004). The main applications of these steels are in the chemical, pharmaceutical, and oil extraction industries, in valves, heat exchangers, pressure vessels, and other applications (Juho Talonen, 2007). Solid-state phase transformations in steels play an essential role in physical metallurgy. 304L austenitic stainless steel are metastable austenitic alloys that can undergo deformation-induced phase transformation (TRIP effect - transformation induced plasticity) (Mangonon \& Thomas, 1970). With the plastic deformation, these steels exhibit an accelerated hardening, mainly resulting from the formation of $\alpha$ 'martensite. There is a substantial increase in strength and also in toughness, owing to the prolongation of the time to start the necking (Spencer et al., 2004; Juho Talonen, 2007). Martensitic transformation during deformation depends on temperature, chemical composition, stress state, and strain rate (Hecker, Stout, Staudhammer, \& Smith, 1982; Murr et al., 1982; Spencer et al., 2004; Juho Talonen, 2007). Numerous papers have studied transformation induced plasticity in austenitic stainless steels. Some examples:(Hecker et al., 1982; Mangonon \& Thomas, 1970; Murr et al., 1982; Nagy, Mertinger, Tranta, \& Sólyom, 2004; Nakajima, Akita, Uematsu, \& Tokaji, 2010; Okayasu, Fukui, Ohfuji, \& Shiraishi, 2013; Palma-Elvira et al., 2019; Rodríguez-Martínez, Rusinek, \& Pesci, 2010; Spencer 
et al., 2004; J. Talonen, Aspegren, \& Hänninen, 2004; Juho Talonen, 2007; Tavares, Pardal, da Silva, Abreu, \& da Silva, 2009; Tsuchida et al., 2011; Weiß, Gutte, \& Mola, 2016; Xu, Zhang, Cheng, \& Song, 2012).

In tests where the deformation rates are moderate to high, the amount of martensite is smaller. So, the martensite volume fraction decreases with increasing strain rate owing to the effect of temperature (Hecker et al., 1982; Juho Talonen, 2007). Austenitic stainless steels are susceptible to transformation via displacement of atomic planes, and two distinct types of martensite can be formed: martensite $\varepsilon$, a paramagnetic phase, presenting structure hexagonal compact (HC), and ferromagnetic martensite $\alpha^{\prime}$, presenting structure body-centered cubic (BCC). Martensitic transformation is related to stacking fault energy (SFE), a parameter influenced by temperature and chemical composition of austenite (Galindo-Nava \& Rivera-Díaz-del-Castillo, 2017; Grässel, Krüger, Frommeyer, \& Meyer, 2000; Ju, Koyama, Sawaguchi, Tsuzaki, \& Noguchi, 2016; Shao et al., 2016; Tavares et al., 2009; Weiß et al., 2016). Martensite is formed by deformation because the energy required for this transformation is less than the energy required to form deformation twins. Research on martensitic transformation into austenitic stainless steels has been carried out frequently, as previously mentioned. Many studies involve monotonic loading related to the formed martensite (Galindo-Nava \& Rivera-Díaz-del-Castillo, 2017; Palma-Elvira et al., 2019; Juho Talonen, 2007). In practice, these steels are subject to diverse types of loading, possibly with stress concentrators.

Thus, some studies that combine monotonic loading and stress concentrators are present in the literature. For example, Okayasu and coauthors (Okayasu et al., 2013) studied the effects of this transformation on samples possessing a stress concentrator in interrupted tensile testing. They found that martensitic transformation occurs up to $1.7 \mathrm{~mm}$ from the notch. Huang and coauthors (Huang, Matlock, \& Krauss, 1989) also analyzed the extent of the formed martensite and reached some $5.0 \mathrm{~mm}$ of the fractured region. Other studies link cyclic loading with martensitic transformation. For example, Maier and coauthors (Maier, Schneeweiss, \& Donth, 1993) investigated fatigue-induced martensitic phase transformation in an AISI 304L tested at low temperatures, $-170^{\circ} \mathrm{C}$ and $-70^{\circ} \mathrm{C}$. They observed that the martensite formation rate increased with decreasing temperature. However, the maximum $\alpha^{\prime}$ - martensite volume fraction formed at both temperatures remained roughly the same. They also found out that the amount of $\alpha^{\prime}$ - martensite causes an increase in cyclic stress amplitude during deformation.

Furthermore, they observed that cyclic deformation might provide a martensite volume fraction higher than that resulting from monotonic deformation. Xu and coauthors (Xu et al., 2012) analyzed the martensitic transformation induced by deformation in an AISI 304L subjected to cyclic tensile loading and unloading by in situ X-ray diffraction compared to conventional monotonic tensile loading. They concluded that the cyclic tensile loading and unloading increased the hardening and the deformation-induced martensite volume fraction compared to the traditional monotonic loading, consequently increasing the TRIP effect. They showed that the martensite increases after each unloading in more significant deformations due to the change in internal structure that involves the internal stress and dislocations configuration when the unloading occurs. Nakajima and coauthors (Nakajima et al., 2010) studied the influence of deformation-induced martensitic transformation on fatigue behavior in 304 stainless steels deformed in rotational bending fatigue tests conducted at room temperature and in a $3 \% \mathrm{NaCl}$ solution. The specimens also were submitted to the tensile-prestrains of $15 \%, 30 \%$, and $60 \%$. Martensite phase increased with increasing prestrain and with stress cycling at the fatigue limit stress in the $30 \%$ and $60 \%$ prestrained specimens. Recently, high Mn austenitic steels have received much attention as potential damping materials for buildings because of their superior low cycle fatigue properties (Ju et al., 2016). The studies cited above show the importance of this subject. To contribute to the literature, 304L steel samples with stress concentrators underwent interrupted monotonic tensile tests. Optical microscopy $(\mathrm{OM})$ and $\mathrm{x}$-ray diffraction (XRD) technique characterized the martensitic transformation. Other $304 \mathrm{~L}$ steel samples with a stress concentrator underwent a low cycle fatigue test. In this case, it was possible to follow the martensitic transformation with the electron backscatter diffraction technique (EBSD).

\section{Materials and Methods}

The 304L austenitic stainless steel used in this work is of industrial origin. The chemical composition, provided by the manufacturer, is given in Table 1.

Table 1. Chemical composition of 304L steel

\begin{tabular}{llllllllll}
\hline Element & $\mathrm{C}$ & $\mathrm{Mn}$ & $\mathrm{Si}$ & $\mathrm{P}$ & $\mathrm{S}$ & $\mathrm{Cr}$ & $\mathrm{Ni}$ & $\mathrm{Mo}$ & $\mathrm{Al}$ \\
\hline $\mathrm{wt} \%$ & 0.018 & 1.27 & 0.479 & 0.0303 & 0.0015 & 18.36 & 8.02 & 0.026 & 0.0032 \\
\hline Element & $\mathrm{Cu}$ & $\mathrm{Co}$ & $\mathrm{V}$ & $\mathrm{Nb}$ & $\mathrm{Pb}$ & $\mathrm{B}$ & $\mathrm{Ti}$ & $\mathrm{Sn}$ & $\mathrm{W}$ \\
\hline $\mathrm{wt} \%$ & 0.043 & 0.102 & 0.042 & 0.0071 & 0.001 & 0.006 & 0.0018 & 0.0044 & 0.015 \\
\hline
\end{tabular}




\subsection{Interrupted Monotonic Tests}

In order to carry out the interrupted tensile tests, the company supplied $6 \mathrm{~mm}$ thick annealed hot-rolled sheets. In the samples, except for the thickness value, all other measurements were the same as those used by (Okayasu et al., 2013). Including a stress concentrator. The specimen cutting procedure was performed with electron erosion. This procedure minimizes the deformation-induced martensitic transformation of the as-received material. To perform the tests, the universal uniaxial tensile testing machine used was the EMIC DL60000. The equipment has an operating capacity of $600 \mathrm{kN}$. To measure the sample deformation, the Emic Electronic Extensometer model EE09 was used. All tests were performed at a speed of $1.71 \mathrm{~mm} / \mathrm{min}$ at room temperature in order to follow the same procedure used by (Okayasu et al., 2013). In order to obtain a strain rate of $5 \times 10^{-4} \mathrm{~s}^{-1}$. The tests were interrupted at different points, represented by points A to E, different stresses were obtained, as shown in Table 2.

The $0.2 \%$ offset yield strength was used to obtain yield point. The ultimate tensile strength was the maximum stress that the material could withstand while being strained. The fracture point was obtained by breaking limit, that is, the point beyond which if further stress is applied the sample will rupture.

Table 2. Stress at each test stopping point. AR - As received; $\sigma_{\mathrm{y}}$ is the yielding point $(0.2 \%$ offset yield strength); $\sigma_{u}-$ the ultimate tensile strength (maximum stress); $\sigma_{\mathrm{f}}-$ the fracture point (breaking limit)

\begin{tabular}{lll}
\hline Points & Stress $(\mathrm{MPa})$ & \\
\hline A & 0 & AR \\
B & 510 & $\sigma_{\mathrm{y}}$ \\
C & 654 & $\left(\sigma_{\mathrm{y}}+\sigma_{\mathrm{u}}\right) / 2$ \\
D & 798 & $\sigma_{\mathrm{u}}$ \\
E & 661 & $\sigma_{\mathrm{f}}$ \\
\hline
\end{tabular}

\subsection{Optical Microscopy and X-Ray Diffraction - Tensile Tests}

The samples were analyzed at their gage length of the tensile specimen. The specimens were ground with emery paper down to 2500 mesh. The samples were metallographically polished with $1 \mu \mathrm{m}, 0.3 \mu \mathrm{m}$, and $0.05 \mu \mathrm{m}$ alumina abrasive. Two different etchants were used. Electrolytic etching with a mixture of $60 \mathrm{ml}$ nitric acid and $40 \mathrm{ml}$ distilled water was used to reveal the austenite grain boundaries. The etching was carried out at $1.0 \mathrm{~V}$, and the etching time was about $8 \mathrm{~min}$. To reveal the $\alpha^{\prime}$ - martensite phase, a mixture of two solutions was used: $0.15 \mathrm{~g}$ sodium-metabisulfite in $100 \mathrm{ml}$ distilled water and $10 \mathrm{ml}$ hydrochloric acid in $100 \mathrm{ml}$ distilled water (Juho Talonen, 2007). Each sample was immersed in the solution for 60 seconds. The samples were examined with an Olympus BX51M optical microscope. Ten micrographs each sample were analyzed by public domain software image J. Austenite grain size, obtained by linear intercepts, and martensite volume fraction, obtained by area fraction was carried out by conventional quantitative metallography techniques (Russ \& Dehoff, 2000). X-ray diffraction (XRD) equipment was used in this investigation. Consisted of a Shimadzu XRD 6000, $\mathrm{Cu} \mathrm{K \alpha}$ tube. Based on (Forouzan, Najafizadeh, Kermanpur, Hedayati, \& Surkialiabad, 2010), the phases associated with the plans were identified.

\subsection{Low Cycle Fatigue Tests}

The same 304L steel of chemical composition shown in Table 1 was used for the low cycle fatigue test. Three specimens were made to replicate and obtain average values, with the geometry shown in Figure 1, from a $1 \mathrm{~mm}$ thick industrially annealed hot-rolled sheet. Besides, a circular discontinuity of $2 \mathrm{~mm}$ in diameter was made in its central region by electron erosion.

The samples were subjected to cyclic loading through fatigue test in tensile-tensile mode by strain control under the following conditions, number of cycles $=40$, strain $=0.025$, nominal stress $680 \mathrm{MPa}$, frequency $=1 \mathrm{~Hz}$, at room temperature, executed by the Instron model 8801 servo-hydraulic machine with a capacity of 100KN load. The obtained stress is between the yield strength and ultimate tensile strength presented in Table 1 for the monotonic tensile test, and therefore, the fatigue test is low cycle. The frequency of $1 \mathrm{~Hz}$ was chosen to avoid weaker plastic deformation resulting from high cyclic loading speed, as seen by Nakajima and coauthors (Nakajima et al., 2010). They used a frequency of $53 \mathrm{~Hz}$. 


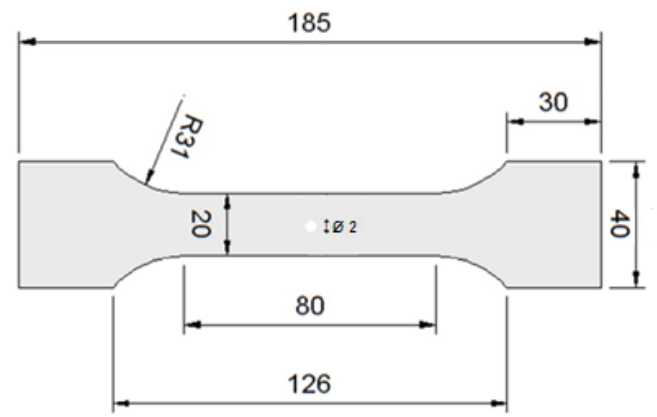

Figure 1. Schematic illustration of the test specimen. Units-mm

\subsection{EBSD- Low Cycle Fatigue Tests}

A sample of $304 \mathrm{~L}$ steel presented in item 2.3 was analyzed before the fatigue test. The sample was cold mounting with a maximum cure temperature of $80^{\circ} \mathrm{C}$ for approximately 24 hours to avoid any phase transformation in this procedure. It was then grounded as presented in item 2.2 and then polished with $3 \mu \mathrm{m}$ and $1 \mu \mathrm{m}$ diamond paste. Final polishing was performed with colloidal silica for 100 minutes. The sample will be called in the text, initial sample (IS).

The samples after the fatigue test were cut in the gage length of the specimen, shown in Figure 1, and then underwent the same procedure described in the previous paragraph. This whole procedure was necessary for the analysis by electron backscatter diffraction technique (EBSD), because the optical microscopy and x-ray diffraction techniques were not able to visualize the martensitic transformation so close to the notch. The sample's microstructural characterization was carried out with the aid of the EBSD technique coupled to the Scanning Electron Microscope (SEM). Data collection was performed in the longitudinal section of the sample in SEM, model EVO MA10, with LaB6 filament. The parameters used in the equipment were: electron beam acceleration= $15 \mathrm{kV}$, beam current $=1.7 \mathrm{nA}$, spot size $=550$, work distance $=23.5 \mathrm{~mm}$, magnification $=1500 \mathrm{x}$, step size $=0.5 \mu \mathrm{m}$. The data obtained were analyzed with the aid of the OIM Data Collection software.

\section{Results and Discussion}

\subsection{Interrupted Tensile Tests}

Figures $2 \mathrm{a}$ and $2 \mathrm{~b}$ show micrographs of $304 \mathrm{~L}$ steel of the AR sample. Figure 2a shows the austenitic grain boundaries. The austenitic grain size was $30 \mu \mathrm{m}$. Figure $2 \mathrm{~b}$ displays a region $1 \mathrm{~mm}$ distant from the notch. Figures $2 \mathrm{c}-2 \mathrm{f}$ depict the micrographs corresponding to the tensile tested sample until fracture of a region $1 \mathrm{~mm}$ distant from the notch.

Figures $2 \mathrm{~b}-2 \mathrm{f}$ micrographs obtained in this paper are similar to those found by Talonen (Juho Talonen, 2007) in his study. Point A indicated in Figure $2 b$ already shows the martensitic phase present in the sample. This may be due to some material preparation step. However, the quantity of martensite is small. After deforming the material, the martensitic phase became more visible, Figure $2 \mathrm{c}-2 \mathrm{f}$. The martensite phase is in darker colors, which becomes more intense according to the plastic deformation. Figures $2 \mathrm{c}$ and $2 \mathrm{~d}$ show lath martensite. In Figures $2 \mathrm{e}$ and $2 \mathrm{f}$, in addition to the laths, the martensite also has the "percolating cluster morphology" (Juho Talonen, 2007). Talonen found a similar martensite morphology for high deformations (Juho Talonen, 2007). The black and dark blue areas present in the micrographs correspond to an increase in martensite volume fraction.

Figure 3 shows the martensite volume fraction measured at the point closest to the notch, $1 \mathrm{~mm}$, and at a point $5 \mathrm{~mm}$ apart from the notch for each sample shown in Table 2. Around $5 \mathrm{~mm}$ from the notch, the martensite volume fraction decreased in comparison to $1.0 \mathrm{~mm}$ from the notch. In other words, the stress concentrator influenced the formation of martensite in the region near the notch. In the fractured sample, Sample E in Table 2, with more extensive deformation, the martensite volume fraction decreases compared to the area analyzed at $1.0 \mathrm{~mm}$ but still has a considerable fraction of martensite, around $20 \%$. Figure 4 shows a mapping of the martensitic transformation from $1 \mathrm{~mm}$ to $5.5 \mathrm{~mm}$ of the notch for all samples. There is a higher concentration of martensite in the region around the notch. From $5.5 \mathrm{~mm}$ onwards, all samples have micrographs like AR. Okayasu and coauthors (Okayasu et al., 2013) found similar results. In the case of their work, the microstructure of the fractured sample resembles the AR sample after $1.7 \mathrm{~mm}$ of the fracture. 


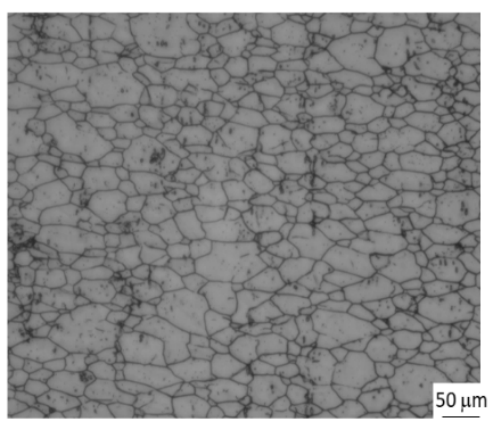

(a)

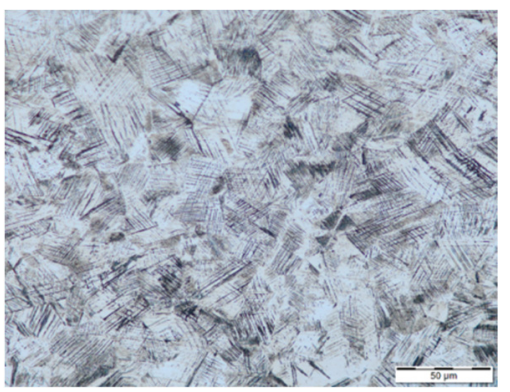

(c)

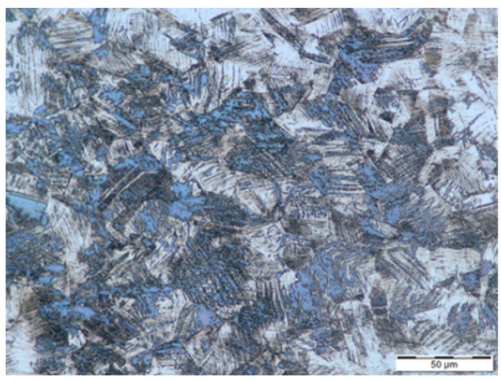

(e)

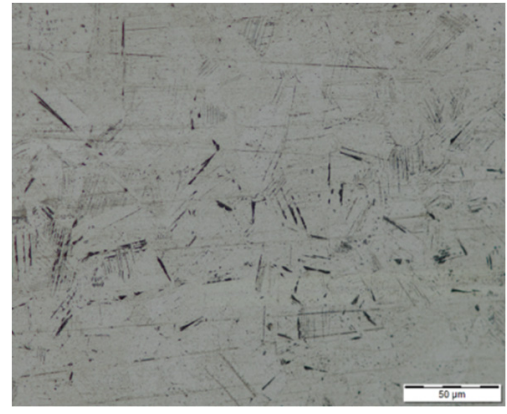

(b)

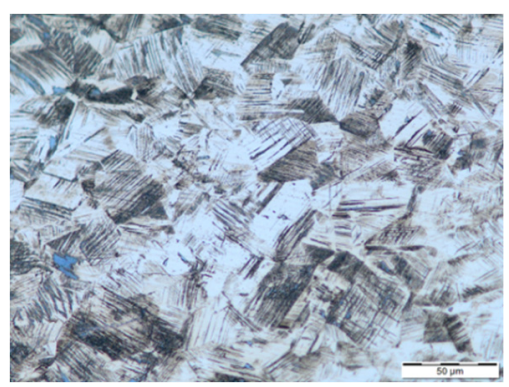

(d)

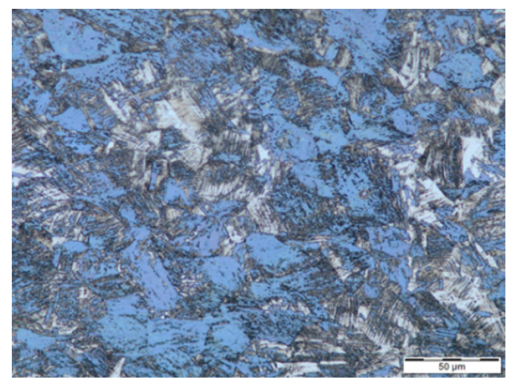

(f)

Figure 2. Sample micrographs: a) As received - austenitic grains; b) As received - Martensite; c) Offset yielding point; d) Between yield point and ultimate tensile strength; e) Ultimate tensile strength; f) Fracture point. Figures $2 \mathrm{~b}$ a $2 \mathrm{f}$ - austenite - white, martensite - dark

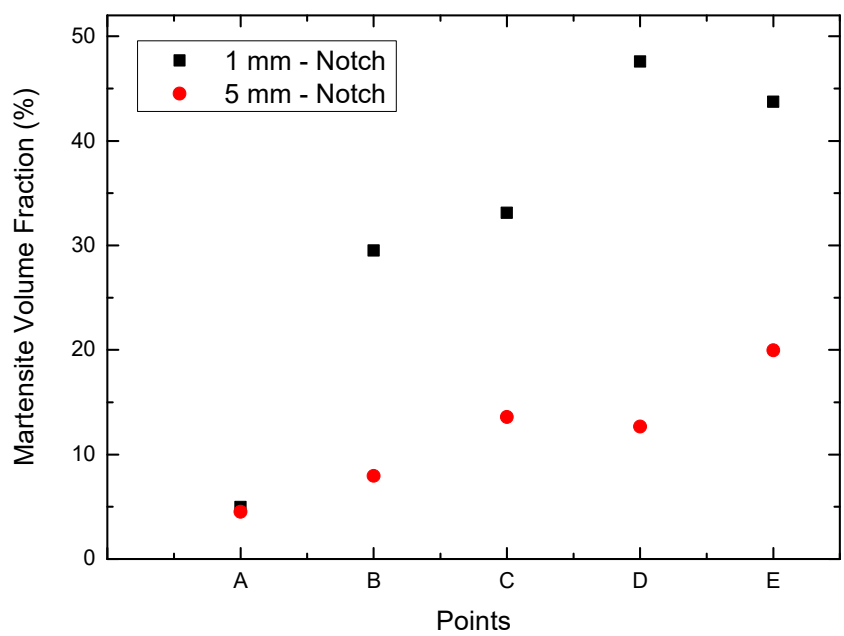

Figure 3. Martensite volume fraction concerning $1 \mathrm{~mm}$ and $5 \mathrm{~mm}$ of the notch. Measurement error values were less than 5\% 


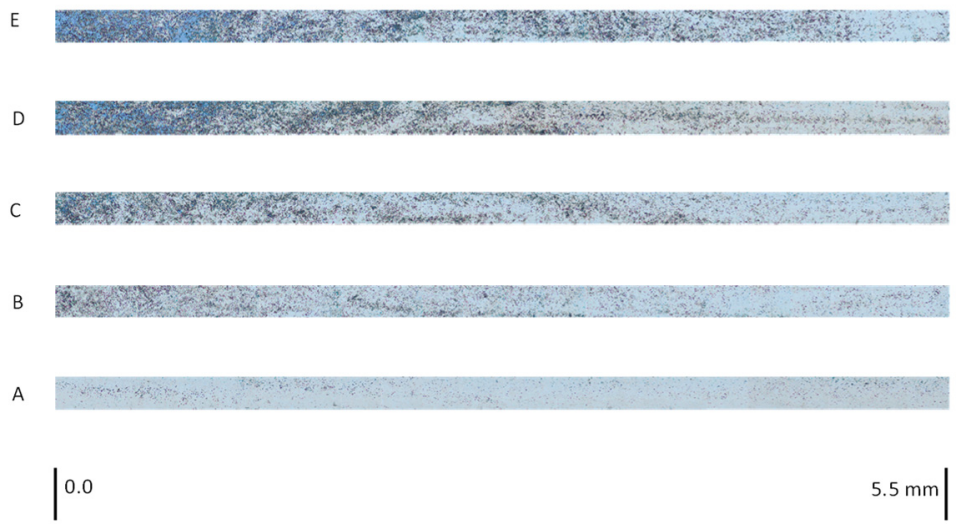

Figure 4. Samples micrograph map: A) As received; B) Offset yielding point; C) Between yield point and ultimate tensile strength; D) Ultimate tensile strength; E) Fracture point, from the notch region at 5.5mm. Austenite - white, martensite - dark

Figure 5 shows the $\mathrm{x}$-ray pattern obtained for each sample. X-ray diffraction corroborated the optical microscopy data. Figure 5 shows the diffraction spectrum for the sample AR (A). The austenite-associated peaks $(\gamma)$ for the diffracted planes, which are (111), (200) and (220) are presented. In this spectrum, no martensite peaks were observed. Since initially the amount of martensite is less than $5 \%$, Figures $2 \mathrm{~b}, 3$, and 4 , the XRD technique was not able to detect it. For the yield limit sample (B), a small growth of the $\alpha^{\prime}$ martensite peak was observed for the diffracted plane (111). Note also the decrease in austenite peaks, $\gamma$. In the sample referring to the intermediate region of yield strength and ultimate tensile strength, $\mathrm{C}$, there was a decrease in the austenite peak and the $\alpha^{\prime}-$ martensite peak stabilization. Once again, the decrease in austenite peaks is observed. These results are reasonable because the increase of martensite is related to the plastic deformation of each sample. Finally, the XRD patterns referring to the ultimate tensile strength and rupture limit samples, D and E, respectively, show that the peaks of martensite and austenite appear with less intensity and less definition concerning sample B and C, respectively. Samples D and E underwent necking and fracture, respectively. So, the area that responds to the x-ray diffraction phenomenon, the planar section, is farthest from the notch (samples D and E). So farther from the notch, there is less strain-induced martensite.

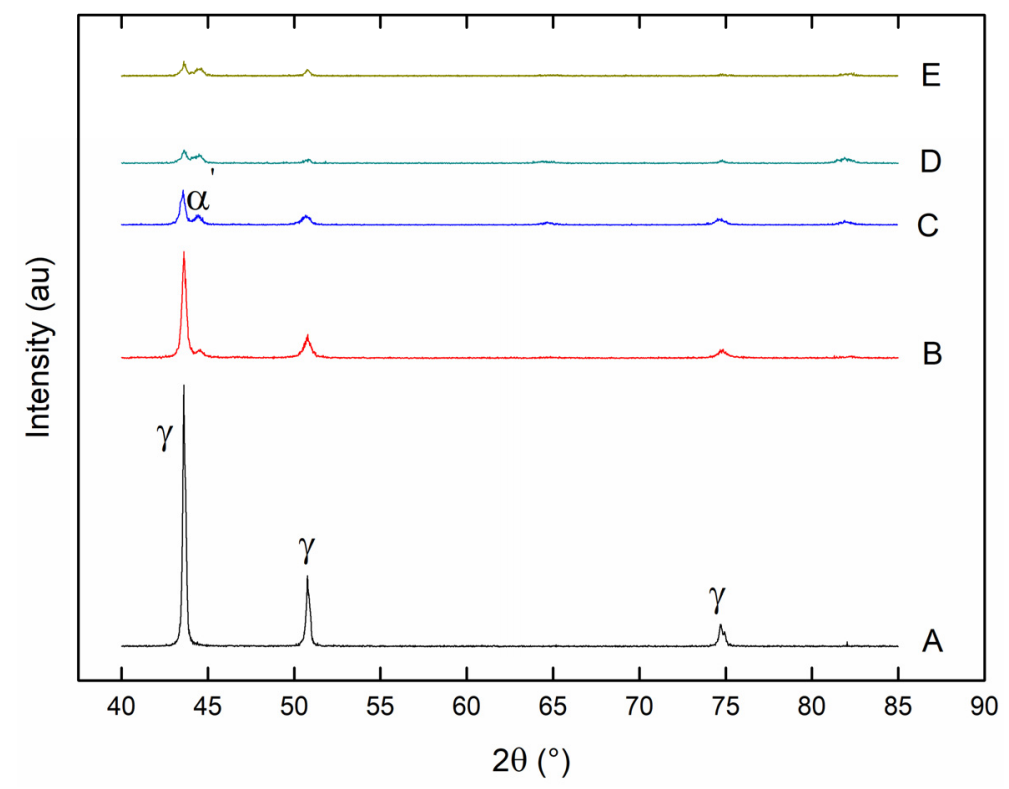

Figure 5. X-ray diffraction patterns: A) As Received; B) Offset yielding point; C) Between yield point and ultimate tensile strength; D) Ultimate tensile strength; E) Fracture point. $\gamma$ - austenite; $\alpha^{\prime}$ - martensite 


\subsection{Low Cycle Fatigue Tests - Results}

The formation of martensite in a 304L steel with circular discontinuity was analyzed, as described in sections 2.3 and 2.4. Therefore, when examining preliminary results with optical microscopy and $\mathrm{x}$-ray diffraction techniques, it was noted that the OM was not adequate for this kind of loading. Both the OM and the XRD technique presented the problems previously mentioned, such as difficulty in focusing and area for x-ray diffraction. Only austenite peaks could be obtained in XRD, indicating that the region of martensite formation was smaller compared to the results shown in Figures 2 to 5. Therefore, the technique of EBSD coupled with SEM was used to characterize the martensite in its formation and extension. Figure 6 shows the microstructure of the material before the fatigue test. The austenitic grain size was around $30 \mu \mathrm{m}$. That is, although sheets with different thicknesses were used for monotonic tests $(6 \mathrm{~mm})$ and fatigue tests $(1 \mathrm{~mm})$, the initial grain size was the same. Also, Figure 6 demonstrates that the grains have a random distribution of crystalline directions.
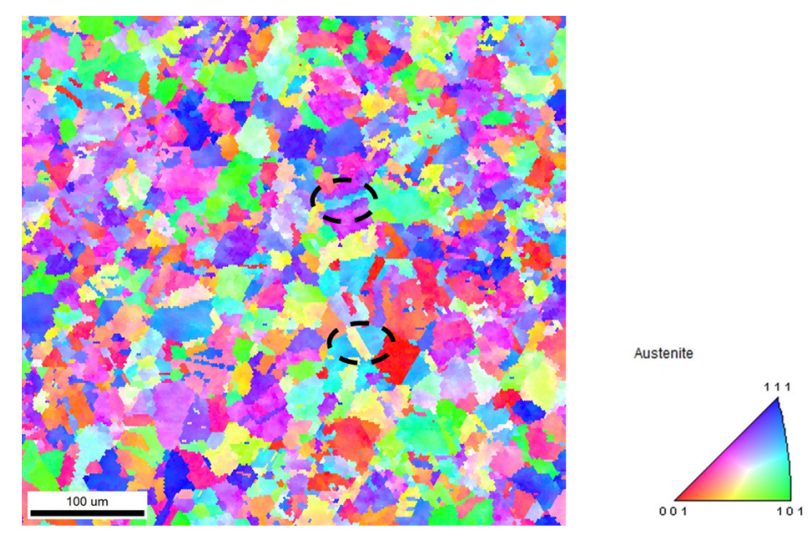

Figure 6. Crystal orientation map of 304L austenitic stainless steel before fatigue testing. Initial sample (IS). Dotted circles highlight the twins

The microstructure formed in the deformed sample after the low cycle fatigue test is shown in Figure 7. It is noticeable the presence of martensite (green), with a very high concentration in the region around $15 \mu \mathrm{m}$ distant from the notch. Figure 7a shows a phase map of the region near the notch, up to $400 \mu \mathrm{m}$. In Figure $7 \mathrm{~b}$, there is a highlight in the region around $30 \mu \mathrm{m}$ from the notch.

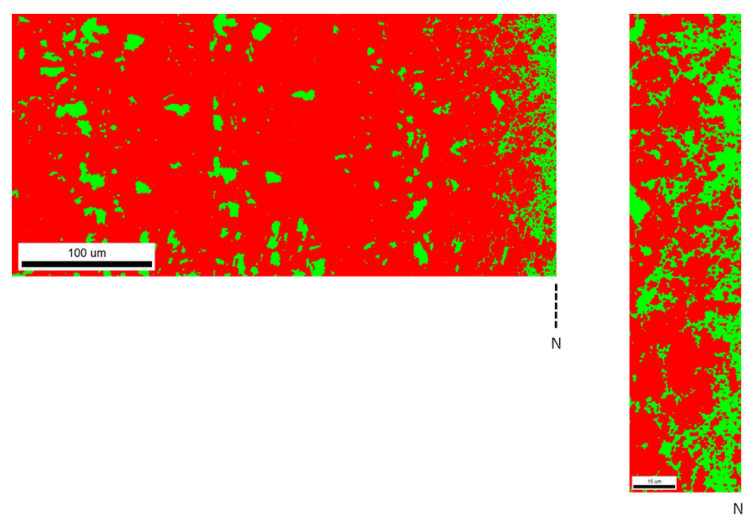

Figure 7. Orientation imaging microscopy map of 304L austenitic stainless steel after fatigue testing. a) Notch region up to $400 \mu \mathrm{m}$, b) Highlight the notch region, around $30 \mu \mathrm{m}$. Austenite - red; martensite - green. N - Notch

The volume fraction of the phases was measured. Of course, a statistical validation is compromised because the martensite is more concentrated in the region very close to the notch, Figure $7 \mathrm{~b}$. The austenite volume fraction in Figure $7 \mathrm{a}$ was $89 \%$, and the martensite volume fraction was $11 \% .400 \mu \mathrm{m}$ away from the notch, the microstructure resembles sample IS again, Figure 6. Already the austenite volume fraction in Figure $7 \mathrm{~b}$ was $68 \%$, and the 
martensite volume fraction was $32 \%$. This suggests that the formation of martensite takes place in a region close to the stress concentrator. The formed martensite is $15 \mu \mathrm{m}$ from the notch, Figure $7 \mathrm{~b}$. Figures 3 and 4 compared to Figure 7, clarify how the difference in loading (monotonic and cyclic) and stress concentrator in the samples influenced the amount of martensite formed. In the samples that underwent monotonic loading with plastic deformation (B to E - Table 2), there was a large amount of martensite formed, up to $1 \mathrm{~mm}$ of notch distance, between 30 and 50\%, Figure 3. With the notch spacing larger than $5 \mathrm{~mm}$, the samples (B to E-Table 2) again have a micrograph like AR, Figure 4. In the sample, which underwent cyclic loading, the amount of martensite formed is also high, but in a region very close to the notch, around $15 \mu \mathrm{m}$, Figure $7 \mathrm{~b}$. At $0.5 \mathrm{~mm}$ from the notch, martensite formation is suppressed. The amount of martensite formed in sample $\mathrm{C}$, Table 2, after monotonic testing, which is the deformed sample between yielding strength and ultimate tensile strength, Figures 3 and 4 , is around $30 \%$ at $1 \mathrm{~mm}$ from the notch. The sample tested in low cycle fatigue, i.e., also between yielding strength and ultimate tensile strength, showed $32 \%$ martensite, Figure $7 \mathrm{~b}$, but at approximately $30 \mu \mathrm{m}$ from the notch. This result suggests that cyclic loading and notch concentrated martensite formation to a small region of the material. Figure 8 shows the austenite, colored, and martensite phase in black in the region closest to the notch.
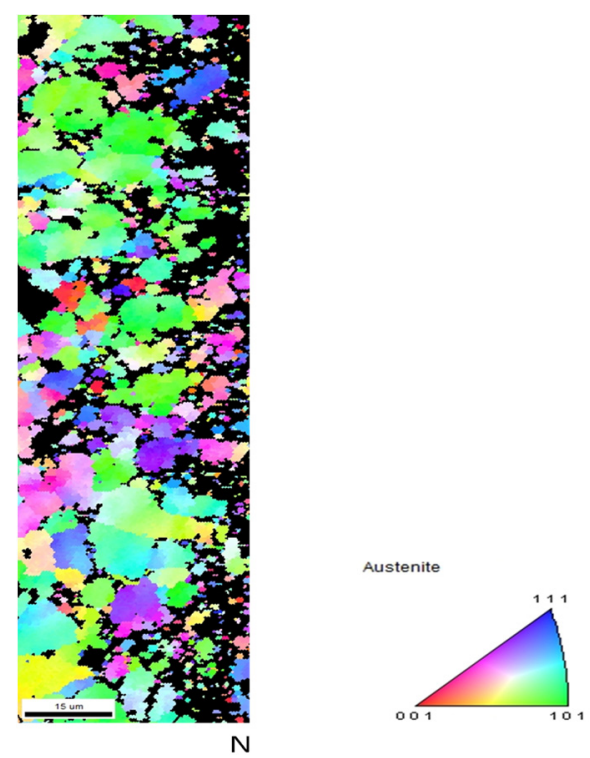

Figure 8. Crystal orientation map of 304L austenitic stainless steel after fatigue testing. Austenite - colored and martensite - black. N - Notch

Austenite in the deformed sample after fatigue testing, Figure 8, as shown in the sample IS, Figure 6, does not have a preferential crystallographic direction. The austenite grains in the deformed sample, Figure 8 , are smaller than the IS sample $(30 \mu \mathrm{m})$, Figure 6 , but this information is visual only. The measure would not have statistical consistency.

\section{Conclusions}

This work studied the deformation-induced martensite in a 304L austenitic stainless steel after interrupted monotonic tests and low cycle fatigue tests. The main conclusions were:

- Initially, the sample consists of austenite grains of approximately $30 \mu \mathrm{m}$ in size. After interrupted monotonic tests, for small deformations lath martensite forms. For larger deformations, besides lath martensite the martensite also exhibits the percolating cluster morphology;

- The samples after the interrupted monotonic tests, present a high-volume fraction of martensite formed $1 \mathrm{~mm}$ away from the notch $(30 \%$ to $50 \%)$, due to the plastic deformation suffered. From $5.5 \mathrm{~mm}$ onwards all samples have micrographs like AR;

- The XRD technique is not suitable to estimate the martensite volume fraction in samples with stress concentrators. After the plastic deformation, the area that responds to the x-ray diffraction phenomenon, i.e., the planar area, is farthest from the notch. So farther from the notch has less strain-induced martensite. Nevertheless, it was possible to confirm the presence of martensite in the deformed samples after interrupted monotonic tests; 
- For the sample with circular discontinuity, after the low cycle fatigue test, the presence of deformation-induced martensite could only be verified with the aid of the EBSD technique. With the aid of this technique, it was proved that the high concentration of martensite formed around $15 \mu \mathrm{m}$ from the discontinuity. Approximately $0.5 \mathrm{~mm}$ from the circular discontinuity, the sample again has a microstructure like the initial sample (IS).

- The amount of martensite formed in the deformed sample, in a monotonic test, between the yielding point and ultimate tensile strength is around $30 \%$ within a region $1 \mathrm{~mm}$ from the notch. The sample tested in low cycle fatigue, i.e., also between yielding strength and ultimate tensile strength, showed $32 \%$ martensite, but at approximately $30 \mu \mathrm{m}$ from the notch. This result suggests that under cyclic loading in a notched specimen, martensite formation took place within a small region of the material.

\section{Acknowledgements}

This research was funded by Fundação de Amparo a Pesquisado Estado do Rio de Janeiro (FAPERJ), grant number: E-26/203.238/2016; Conselho Nacional de Desenvolvimento Científico e Tecnológico (CNPq) and Coordenação de Aperfeiçoamento de Pessoal de Nível Superior (CAPES)—Finance Code 001.

\section{Conflict of interests}

The authors declare that there is no conflict of interests regarding the publication of this paper.

\section{References}

Forouzan, F., Najafizadeh, A., Kermanpur, A., Hedayati, A., \& Surkialiabad, R. (2010). Production of nano/submicron grained AISI 304L stainless steel through the martensite reversion process. Materials Science and Engineering A, 527(27-28), 7334-7339.

Galindo-Nava, E. I., \& Rivera-Díaz-del-Castillo, P. E. J. (2017). Understanding martensite and twin formation in austenitic steels: A model describing TRIP and TWIP effects. Acta Materialia, 128, 120-134.

Grässel, O., Krüger, L., Frommeyer, G., \& Meyer, L. W. (2000). High strength Fe-Mn-(Al, Si) TRIP/TWIP steels development - properties - application. International Journal of Plasticity, 16(10), 1391-1409.

Hecker, S. S., Stout, M. G., Staudhammer, K. P., \& Smith, J. L. (1982). Effects of Strain State and Strain Rate on Deformation-Induced Transformation in 304 Stainless Steel: Part I. Magnetic Measurements and Mechanical Behavior. Metallurgical Transactions A, 13(4), 619-626.

Huang, G. L., Matlock, D. K., \& Krauss, G. (1989). Martensite formation, strain rate sensitivity, and deformation behavior of type 304 stainless steel sheet. Metallurgical Transactions A, 20(7), 1239-1246.

Ju, Y. B., Koyama, M., Sawaguchi, T., Tsuzaki, K., \& Noguchi, H. (2016). In situ microscopic observations of low-cycle fatigue-crack propagation in high-Mn austenitic alloys with deformation-induced $\epsilon$-martensitic transformation. Acta Materialia, 112, 326-336.

Maier, H. J., Schneeweiss, O., \& Donth, B. (1993). Kinetics of fatigue-induced phase transformation in a metastable austenitic 304L-type steel at low temperatures. Scripta Metallurgica et materialia, 29(4), 521-526.

Mangonon, P. L., \& Thomas, G. (1970). The martensite phases in 304 stainless steel. Metallurgical Transactions, 1(6), 1577-1586.

Murr, L. E., Staudhammer, K. P., Hecker, S. S., Stout, M. G., Staudhammer, K. P., Murr, L. E., \& Smith, J. L. (1982). Effects of Strain State and Strain Rate on Deformation-Induced Transformation in 304 Stainless Steel : Part 1. Microstructural Study. Metallurgical Transactions A, 13(April), 627-635.

Nagy, E., Mertinger, V., Tranta, F., \& Sólyom, J. (2004). Deformation induced martensitic transformation in stainless steels. Materials Science and Engineering A, 378(1-2 SPEC. ISS.), 308-313.

Nakajima, M., Akita, M., Uematsu, Y., \& Tokaji, K. (2010). Effect of strain-induced martensitic transformation on fatigue behavior of type 304 stainless steel. Procedia Engineering, 2(1), 323-330.

Okayasu, M., Fukui, H., Ohfuji, H., \& Shiraishi, T. (2013). Strain-induced martensite formation in austenitic stainless steel. Journal of Materials Science, 48(18), 6157-6166.

Palma-Elvira, E. D., Garnica-Gonzalez, P., Pacheco-Cedeño, J. S., Cruz Rivera, J. J., Ramos-Azpeitia, M., Garay-Reyes, C. G., \& Hernández-Rivera, J. L. (2019). Microstructural development and mechanical properties during hot rolling and annealing of an automotive steel combining TRIP/TWIP effects. Journal of Alloys and Compounds, 798, 45-52. 
Rodríguez-Martínez, J. A., Rusinek, A., \& Pesci, R. (2010). Experimental survey on the behavior of AISI 304 steel sheets subjected to perforation. Thin-Walled Structures, 48(12), 966-978.

Russ, J. C., \& Dehoff, R. (2000). In Practical Stereology (2nd ed., pp. 45-78). New York, NY, USA: Kluwer Academic/Plenum Publishers.

Shao, C. W., Zhang, P., Liu, R., Zhang, Z. J., Pang, J. C., \& Zhang, Z. F. (2016). Low-cycle and extremely-low-cycle fatigue behaviors of high-Mn austenitic TRIP/TWIP alloys: Property evaluation, damage mechanisms and life prediction. Acta Materialia, 103, 781-795.

Spencer, K., Embury, J. D., Conlon, K. T., Véron, M., \& Bréchet, Y. (2004). Strengthening via the formation of strain-induced martensite in stainless steels. Materials Science and Engineering A, 387-389(1-2 SPEC. ISS.), 873-881.

Talonen, J., Aspegren, P., \& Hänninen, H. (2004). Comparison of different methods for measuring strain induced $\alpha$-martensite content in austenitic steels. Materials Science and Technology, 20(12), 1506-1512.

Talonen, Juho. (2007). Effect of strain-induced $\alpha$ '-martensite transformation on mechanical properties of metastable austenitic stainless steels (Doctoral dissertation). Helsinki University of Technology, Espoo, Finland.

Tavares, S. S. M., Pardal, J. M., da Silva, M. J. G., Abreu, H. F. G., \& da Silva, M. R. (2009). Deformation induced martensitic transformation in a 201 modified austenitic stainless steel. Materials Characterization, 60(8), 907-911.

Tsuchida, N., Morimoto, Y., Tonan, T., Shibata, Y., Fukaura, K., \& Ueji, R. (2011). Stress-Induced Martensitic Transformation Behaviors at Various Temperatures and Their TRIP Effects in SUS304 Metastable Austenitic Stainless Steel. ISIJ International, 51(1), 124-129.

Weiß, A., Gutte, H., \& Mola, J. (2016). Contributions of $\varepsilon$ and $\alpha^{\prime}$ TRIP Effects to the Strength and Ductility of AISI 304 (X5CrNi18-10) Austenitic Stainless Steel. Metallurgical and Materials Transactions A: Physical Metallurgy and Materials Science, 47(1), 112-122.

Xu, Y., Zhang, S. H., Cheng, M., \& Song, H. W. (2012). In situ X-ray diffraction study of martensitic transformation in austenitic stainless steel during cyclic tensile loading and unloading. Scripta Materialia, 67(9), 771-774.

\section{Copyrights}

Copyright for this article is retained by the author(s), with first publication rights granted to the journal.

This is an open-access article distributed under the terms and conditions of the Creative Commons Attribution license (http://creativecommons.org/licenses/by/4.0/). 